\title{
The Analysis of the Effect of Job-hopping from the Angle of Ethics
}

\author{
YuJie HOU ${ }^{1, a,{ }^{*}}$, Hui $\mathrm{ZHU}^{2, \mathrm{~b}}$ and LongJi WEl ${ }^{3, \mathrm{c}}$ \\ 1 Qingdao HuangHai University, Qingdao, 266427, China \\ 2 Qingdao HuangHai University, Qingdao, 266427, China \\ 3 Qingdao HuangHai University, Qingdao, 266427, China

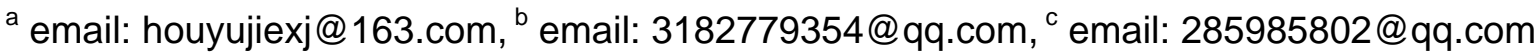

Keywords: Job-hopping,Impact,Ethical,Reasonable,Unreasonable

\begin{abstract}
Job-hopping has become a common phenomenon in today's society, it has been a lot of research on the reason and the countermeasure.This paper analyses job-hopping influence on society, enterprise and individual from the perspective of ethics. The reasonable job-hopping behavior has a positive impact on society ,enterprises and individuals, reflects the ethics of morality and virtue.The unreasonable job-hopping behavior has a negative effect on enterprise and individual, embodies the loss of the ethics of integrity and loyalty.
\end{abstract}

\section{Introduction}

Rapid development of the socialist market economy in our country has made every walk of life assimilate into the tide of economic globalization more deeply, enterprises face new opportunities for development but also face more intense competition. One of the most important aspects is the competition of talents,but employees' job-hopping is rising in some enterprises. Normal employee turnover is very necessary and useful, it can accelerate the metabolism of members of the organization, improve the efficiency of work[1].

"Aaron" refers to the interpersonal relations, namely civilization, "logic" refers to the moral law and principles[2]. Essentially ethics refers to process of the relationship of " oneself " and "people" , which including people with others, people and countries, human and nature[3].

\section{The Positive Impacts on Reasonable Job-hopping}

Aristotle's view is that "Men of virtue is a kind of be kind, and to obtain the outstanding achievement of quality"[4]. According to this character, I think the job-hopping is reasonable which combining their own interests with the interests of others. The reasonable job-hopping behavior has a certain ethical significance either from society ,enterprises or the employee themselves.

Impacts on Society. Not only can job-hopping promote the growth of social economic, and promote the progress and development of social, but also can promote flow and circulation of the talent. In this sense, increasing total social benefits is the ultimate standard of moral, which can embody the virtue. Specific performance in the following areas:

First, reasonable job-hopping can make the fullest use of human resources and promote the great growth and development of social economic. Second, reasonable job-hopping can make a significant contribution to the regional economy. Our Pearl River Delta, Yangtze River Delta regional economy have a rapid development,which is before the middle and west of our country. In addition to geographical reasons, there is a closely relationship with the rapid flow and gather of human resources. Third, Accelerated the rational allocation and effective use of human resources . Spontaneous flow of human resources can promote the stock adjustments, which can make the talent structure more reasonable and effective.

Thus, the ethical functions of job-hopping are prominent : Firstly, make the best use of human resources, eliminate any waste is the virtue economy in the economic sphere; Secondly,the effective utilization of human resources have a huge economic efficiency, which can promote economic 
development and social progress,also can increase the total social benefit.This is the result of a "good" at every historical period; Thirdly, improving the overall quality of people and conducive to the full play of the people's essential strength, which make the development of economic more humane and ethical, so it is good.

Impacts on Enterprise. Reasonable employee job-hopping can encourage enterprises to improve the mechanism and efficiency, which is advantageous to provide more material and spiritual goods for the masses. This is in line with the ethical principles of socialist utilitarianism.Specific performance in:

First, those job-hopping employees who always with the negative attitude of work can help enterprises eliminating the long formation of conflicts and grievances, and improve enterprises' productivity. Second, job-hopping can leave the position for other employees can help enterprises increasing employee new opportunities for promotion and development of space. Third, job-hopping is beneficial to fresh blood, new employees often can bring new ideas and new technology to the enterprise, which is more conducive to enterprises' development innovation.

Thus,the reasonable job-hopping for the enterprise can eliminate the fight of "evil" and improve the unreasonable system which will be more more accord with people's needs and requirements. Thereby enhancing the business efficiency and create wealth, providing basic support for improving people's well-being, so as to showing a positive role in ethics.

Impacts on Individual. Job-hopping advocated the freedom of employees' rights, shows the equal status of the staff and the enterprises. itself has the meaning of ethics.

First, job-hopping can bring vitality and passion. Perennial in a single, fixed work can easily prone to burnout, work ethic gradually subside. Under the background of knowledge economy, job-hopping as well as the body's metabolism and blood circulation can helps employee keeping their vitality. Second, job-hopping is beneficial to enrich and accumulate experience. For employee themselves(especially young people), job-hopping can help them to fully display themselves and accumulate experience in various types of work in a variety of positions. And this experience, within a single type of business or a single type of work is impossible to obtain. Third, job-hopping is helpful to find suitable jobs. Many times people find a job at first and then select. Due to various reasons, they can not find their ideal jobs initially. By job-hopping can gradually find their satisfactory jobs and suitable positions.

Job-hopping brings vitality to employees, highlight the status of human beings as the subject in the economic and social development, which is beneficial to develop the potential and realize the value of employees, which embody the humanistic spirit of ethics.

\section{The negative impacts on unreasonable job-hopping}

The negative impacts on unreasonable job-hopping exist both the enterprises' ethics problems and employees' ethical issues.

Impacts on Enterprise. Those problems, such as unscientific enterprises' system, management loopholes, defects of administrators and so on, are exposed due to unreasonable job-hopping of employees. And it is certain that the economic efficiency of the enterprise, material products and spiritual products of people are decreased, which leads to the loss of moral system, and then loyalty is declined in staff . At the same time, professional ethics of the staff are decay due to unreasonable job-hopping of employees, as a result, enterprises' losses is present due to the immoral behavior of enterprises' employees. the ethical side reflects in:

First, the job-hopping especially the talented person causes significant loss of human capital investment, increases the replacement cost of talents and brings the cost loss of the enterprises.Cost loss includes two aspects: first, the job-hopping means the loss of human capital investment of the employee individuals, which includes recruitment, training cost, etc; Second,the job-hopping brings high turnover costs, that is the replacement cost. A employee leaves his position, the replacement cost of the enterprise amount his salary's 1.5 to 2.5 times[5]. 
Second, the job-hopping may cause the lost of enterprises' intangible assets such as commercial and technical secrets, thus weakening the competitiveness of enterprises and bringing serious loss. Enterprises' top management and important technology talent also master the relevant commercial and technical secrets. Once these brain drain means the corresponding loss of intangible assets, which influences the performance .It can even bring a devastating blow to the enterprises.

Third, the job-hopping may increase the business risk of the enterprises. If employees hope to rival camps the business or orders will be taken away, the funds also cannot be withdrawn from circulation, and they cannot be timely fulfill their contract that will caused economic losses, etc[6].

Fourth, The cohesiveness of enterprises weakened. For enterprises, team members have a strong sense of belonging, members can carefree communication of information each other, high cohesive teamwork will be converted into the most direct productivity. And when employees job-hopping phenomenon occurs in a enterprise, employees' job satisfaction and corporate loyalty will be greatly reduced, the Confidence of the future enterprises' development will be shaken. Especially core employees, executives or core team job-hopping can affect employees more confidence in enterprise development.Once a certain employees' confidence for the enterprises' future development are shaken,the mood will be quickly transmitted to the other employees, and spread to the whole enterprise.

Impact on Employees. Unreasonable employee job-hopping shows a lack of employee loyalty, credit, love and dedication.It is harmful to the overall development of employees. Its non-moral embodies in:

First, Unreasonable employee job-hopping is harmful to work. Frequently job-hopping will make the employees always in a strange environment.they need to relearn and re-establish relations, which is not conducive to doing their own work. Employees frequent job-hopping is unfair for all the enterprises. Because the frequent job-hopping make the labor cannot complete their duty,then the enterprises must increase the corresponding cost and take the losses.On the other hand, Frequently job-hopping reflects the professional dedication and the loss of employees. Love and dedication of the staff is necessary professional ethics.

Second, Unreasonable employee job-hopping is harmful to the development of their own. In the era of knowledge economy, no matter what job you do need to be fully invested and do your best. If employees just pursuit for personal interests by frequently job-hopping, their technical level and business ability cannot be improved which will affect their promotion. The ultimate goal of employee job-hopping is to realize their own value and get freely development.

Third, Unreasonable employee job-hopping is the lack of loyalty and credit. Frequent job-hopping will give a bad impression for the other enterprises. Individual credit weakened in jumped again and again. The enterprises can't deliver them important work in the later work which is bad for their long-term interests and development.

\section{Conclusions}

The job-hopping of enterprise staff results from the development of enterprises and the self-development of the employees is a certainty under the condition of market economy. Rational job-hopping will have a positive impact, however, unreasonable job hopping will have a negative impact.

The reasonable job-hopping brings zest to the employees, and it is beneficial to enrich and accumulate experience of employees. That people plays the main role in the process of social and economic development is highlighted, which manifests the humanistic spirit. In addition, it is beneficial to eliminate redundancies, add fresh blood, improve the mechanism of enterprise and promote the innovation of enterprise. Moreover, it is beneficial to make full use of human resources, exert intelligent advantage, improve the overall quality of human resources, promote progress and development of society. And that reflects the "good".

The unreasonable job-hopping, which results in the loss of human capital investment, increasing the cost of the replacement of talent, weakening the competitiveness of enterprises, weakening the 
cohesion and solidarity of the enterprise and hindering the economic efficiency of enterprises. What's more, it is not beneficial for their own work and the development of their own growth and career. Unreasonable job hopping reflects a lot of problems, such as the lack of faith, the loss of the spirit of dedication and the collapse of professional ethics. As a result, this will hinder the full development of human beings.

\section{Acknowledgement}

In this paper, the research was sponsored by the Education Science Research Subject in Shandong Province (Project No. 15SC186):The research of Vocational Education and Industry Enterprise Integration of System and Mechanism.

\section{References}

[1] Z.M.Wang, J.X.Chen, J.li. Several Organizational Factors Affecting Employee Turnover [J]. Science and Science Technology Management, 2001,11 (In Chinese)

[2] Y.Liang,H.Wang,H.F.Wang. The Impacts of Corporate Ethics on Employee Loyalty [J]. Journal of Economic BBS, 2007, 19 (In Chinese)

[3] Z.Q. Xiao. The Fundamental Question of Ethics [J]. Journal of Moral and Civilization, 2007, 1 (In Chinese)

[4]Aristotle. Nicomachean Ethics [M]. Beijing: China Social Sciences Press, 1999, 35 pages. (In Chinese)

[5] X.Peng. Enterprise Employees "job-hopping" in Ethical Review [D]. Chongqing: Chongqing Normal University, 2009(In Chinese)

[6] H.M.Jiang. Employee Job-hopping, What Would you do? [J]. Journal of Human Resources, 2006, 24 (In Chinese) 